\title{
BIBECHANA
}

A Multidisciplinary Journal of Science, Technology and Mathematics

ISSN 2091-0762 (online)

Journal homepage: http://nepjol.info/index.php/BIBECHANA

\section{Thermodynamic and structural properties of K-Na liquid alloy}

\author{
I. Koirala ${ }^{1,2}$, I. S. Jha ${ }^{3}$, B. P. Singh ${ }^{1^{*}}$ \\ ${ }^{1}$ University Department of Physics, T.M. Bhagalpur University, India \\ ${ }^{2}$ Central Department of Physics, Tribhuvan University, Nepal \\ ${ }^{3}$ M.M.A.M. Campus, Biratnagar, Tribhuvan University, Nepal \\ *Corresponding author: E-mail : bhrigunandansingh@yahoo.com \\ Article history: Received 2 October, 2012; Accepted 16 November, 2012
}

\begin{abstract}
The deviation from ideal mixture behavior and concentration dependent symmetry in thermodynamic and structural properties of $\mathrm{K}-\mathrm{Na}$ liquid alloy is investigated within a simple statistical model. The concentration dependence of the free energy of mixing, heat of mixing, entropy of mixing, concentration fluctuation in the long wavelength limit, Warren-Cowley short range order parameter, ratio of diffusion coefficients of Potassium-sodium alloy at $384 \mathrm{~K}$ and activity of the components has got special attention to show a tendency of like atom pairing in the mixture.
\end{abstract}

Key words: liquid alloy; simple statistical model; thermodynamic properties; diffusion coefficient

\section{Introduction}

The properties of mixing of some binary alloys such as, free energy of mixing, heat of mixing, entropy of mixing are symmetrical about the equiatomic composition [1] even though there is large size difference. Such behaviour of these liquid alloys is least understood and demands extensive theoretical investigations. Since long theoreticians [2-8] are trying to interpret the physical properties of liquid alloys so that their alloying behaviour could adequately be understood.

In the present work we intend to explain the alloying behaviour (the free energy of mixing $\left(G_{M}\right)$, heat of mixing $\left(\mathrm{H}_{\mathrm{M}}\right)$, entropy of mixing $\left(\mathrm{S}_{\mathrm{M}}\right)$ ) of potassium-sodium liquid alloy on the basis of simple statistical model. Thermodynamic parameters give us an idea about the stability and bonding strength of the constituent species of the alloy, whereas structural parameters provide the idea about ordering and segregating nature of the alloy. Some of the properties of mixing of $\mathrm{K}-\mathrm{Na}$ alloys are symmetrical about equiatomic composition despite the large size difference of $\mathrm{Na}$ and $\mathrm{K}[1]$. 
The outline of the paper is follows: In section 2, general formalism about the theory is presented. Section 3 deals with the result and discussion and conclusion are presented in section 4 .

\section{Formalism}

Simple statistical model developed by Singh and Mishra [8] for the binary liquid alloys is a model in which grand partition function is used. The grand partition function is solved by assuming that the energy of a given nearest neighbour bond is different if it belongs to the complex than if it does not. The grand partition function for simple binary liquid alloys can be generalized as

$$
\Xi=\sum_{E} q_{A}^{N_{A}}(T) q_{B}^{N_{B}}(T) \exp \left(\frac{\mu_{A} N_{A}+\mu_{B} N_{B}-E}{k_{B} T}\right)
$$

where $q_{i}^{N_{i}}$ are the partition functions of atoms ( $i=A$ or B ) associated with inner and vibrational degree of freedom. $\mathrm{q}_{\mathrm{i}}$ is the same whether the atom $\mathrm{i}$ is located in the pure state or in alloy. $\mu_{\mathrm{A}}$ and $\mu_{\mathrm{B}}$ are the chemical potentials; $\mathrm{E}$ is the configurational energy; $\mathrm{k}_{\mathrm{B}}$, the Boltzmann constant and $\mathrm{T}$, the absolute temperature. The standard thermodynamical relation for free energy of mixing is [8]

$$
\mathrm{G}_{\mathrm{M}}=\mathrm{G}_{\mathrm{M}}^{\mathrm{XS}}+\mathrm{Nk}_{\mathrm{B}} \mathrm{T} \sum_{\mathrm{i}} \mathrm{C}_{\mathrm{i}} \ln \mathrm{C}_{\mathrm{i}}
$$

But excess of free energy of mixing is

$$
\frac{\mathrm{G}_{\mathrm{M}}^{\mathrm{XS}}}{\mathrm{Nk}_{\mathrm{B}} \mathrm{T}}=\int_{0}^{\mathrm{C}} \ln \sigma^{\mathrm{z}} \mathrm{dC}=\mathrm{C}_{\mathrm{A}} \ln \gamma_{\mathrm{A}}+\mathrm{C}_{\mathrm{B}} \ln \gamma_{\mathrm{B}}
$$

where

$$
\begin{aligned}
\sigma & =(\beta+2 \mathrm{C}-1) \exp \left(-\mathrm{w} / \mathrm{zk}_{\mathrm{B}} \mathrm{T}\right) / 2 \mathrm{C} \\
\gamma_{\mathrm{A}} & =\left[\left(\beta-1+2 \mathrm{C}_{\mathrm{A}}\right) / \mathrm{C}_{\mathrm{A}}(1+\beta)\right]^{\mathrm{z} / 2} \\
\gamma_{\mathrm{B}} & =\left[\left(\beta+1-2 \mathrm{C}_{\mathrm{A}}\right) / \mathrm{C}_{\mathrm{B}}(1+\beta)\right]^{\mathrm{z} / 2} \\
\beta & =\left\{1+4 \mathrm{C}_{\mathrm{A}} \mathrm{C}_{\mathrm{B}}\left[\exp \left(2 \mathrm{w} / \mathrm{zk}_{\mathrm{B}} \mathrm{T}\right)-1\right]\right\}^{1 / 2}
\end{aligned}
$$

Using the relations (2) and (3), the free energy of mixing will be

$$
\begin{array}{rlrl}
\mathrm{G}_{\mathrm{M}} & =\mathrm{Nk}_{\mathrm{B}} \mathrm{T}\left[\mathrm{C}(1-\mathrm{C}) \frac{\mathrm{W}}{\mathrm{k}_{\mathrm{B}} \mathrm{T}}+\mathrm{C} \ln \mathrm{C}+(1-\mathrm{C}) \ln (1-\mathrm{C})\right. \\
\text { Or, } & \frac{\mathrm{G}_{\mathrm{M}}}{\mathrm{RT}} & =\mathrm{C}(1-\mathrm{C}) \frac{\mathrm{w}}{\mathrm{k}_{\mathrm{B}} \mathrm{T}}+\mathrm{C} \ln \mathrm{C}+(1-\mathrm{C}) \ln (1-\mathrm{C})
\end{array}
$$

The Warren-Cowley chemical short range order parameter $\alpha_{1}$ for the first coordination shell $[9,10]$ in term of $\mathrm{w}$ is

$$
\frac{\alpha_{1}}{\left(1-\alpha_{1}\right)^{2} C_{A} C_{B}}=\exp \left(2 \mathrm{w} / \mathrm{zk}_{\mathrm{B}} \mathrm{T}\right)-1
$$

For the equiatomic composition $\left(\mathrm{C}_{\mathrm{A}}=\mathrm{C}_{\mathrm{B}}=\frac{1}{2}\right)$, relation (3) reduces to 


$$
\frac{\mathrm{G}_{\mathrm{M}}^{\mathrm{XS}}}{\mathrm{Nk}_{\mathrm{B}} \mathrm{T}}=\ln 2^{\mathrm{z} / 2}\left[1+\exp \left(-\mathrm{w} / \mathrm{zk}_{\mathrm{B}} \mathrm{T}\right)\right]^{-\mathrm{z} / 2}
$$

From Eq. (4), the concentration fluctuation in the long wavelength limit becomes

$$
\mathrm{S}_{\mathrm{cc}}(0)=\mathrm{Nk}_{\mathrm{B}} \mathrm{T}\left(\frac{\partial^{2} \mathrm{G}_{\mathrm{M}}}{\partial \mathrm{C}^{2}}\right)_{\mathrm{T}, \mathrm{P}, \mathrm{N}}^{-1}=\mathrm{C}_{\mathrm{A}} \mathrm{C}_{\mathrm{B}}[1+(\mathrm{z} / 2 \beta)(1-\beta)]^{-1}
$$

From Eqs. (5) and (7), it follows that

$$
\alpha_{1}=(\mathrm{S}-1) /[\mathrm{S}(\mathrm{z}-1)+1]
$$

where, $\quad \mathrm{S}=\frac{\mathrm{S}_{\mathrm{cc}}(0)}{\mathrm{C}_{\mathrm{A}} \mathrm{C}_{\mathrm{B}}}=\frac{\mathrm{S}_{\mathrm{cc}}(0)}{\mathrm{S}_{\mathrm{cc}}^{\mathrm{id}}(0)}$

and $\mathrm{z}$ represents the number of atoms in the first coordination shell and is called coordination number.

The heat of mixing of binary liquid alloys can be obtained using the standard thermodynamic relation (4):

$$
\begin{aligned}
\mathrm{H}_{\mathrm{M}} & =\mathrm{G}_{\mathrm{M}}-\mathrm{T}\left(\frac{\partial \mathrm{G}_{\mathrm{M}}}{\partial \mathrm{T}}\right)_{\mathrm{N}, \mathrm{P}} \\
& =\mathrm{RT}\left[\mathrm{C}(1-\mathrm{C}) \frac{\mathrm{w}}{\mathrm{k}_{\mathrm{B}} \mathrm{T}}-\mathrm{C}(1-\mathrm{C}) \frac{1}{\mathrm{k}_{\mathrm{B}}} \frac{\mathrm{dw}}{\mathrm{dT}}\right]
\end{aligned}
$$

The entropy of mixing is

$$
\mathrm{S}_{\mathrm{M}}=-\left(\frac{\partial \mathrm{G}_{\mathrm{M}}}{\partial \mathrm{T}}\right)_{\mathrm{N}, \mathrm{P}}=\frac{\mathrm{H}_{\mathrm{M}}-\mathrm{G}_{\mathrm{M}}}{\mathrm{T}}
$$

The activity of binary liquid alloys, ai, can be related to the free energy of mixing by the relation

$$
\mathrm{Nk}_{\mathrm{B}} \mathrm{T} \ln \mathrm{a}_{\mathrm{i}}=\left(\frac{\partial \mathrm{G}_{\mathrm{M}}}{\partial \mathrm{N}_{\mathrm{i}}}\right)_{\mathrm{T}, \mathrm{P}, \mathrm{N}}
$$

The mixing behavior of the alloy forming molten metals can also be studied at the microscopic level in terms of coefficients of diffusion. The $\operatorname{Scc}(0)$ and diffusion coefficients can be related using Darken thermo dynamic equation for diffusion [11] as follows:

$$
\frac{\mathrm{D}_{\mathrm{M}}}{\mathrm{D}_{\mathrm{id}}}=\frac{\mathrm{S}_{\mathrm{cc}}^{\mathrm{id}}(0)}{\mathrm{S}_{\mathrm{cc}}(0)}
$$

Here $D_{\text {id }}$ is the intrinsic diffusion coefficient for an ideal mixture and $D_{M}$ is the chemical or mutual diffusion coefficient given by

$$
\mathrm{D}_{\mathrm{M}}=\mathrm{C}_{\mathrm{A}} \mathrm{D}_{\mathrm{B}}+\mathrm{C}_{\mathrm{B}} \mathrm{D}_{\mathrm{A}}
$$

where $\mathrm{D}_{\mathrm{A}}$ and $\mathrm{D}_{\mathrm{B}}$ are the self-diffusion coefficients of pure components $\mathrm{A}$ and $\mathrm{B}$ respectively. 


\section{Results and Discussion}

\subsection{Thermodynamic properties}

The energy parameter used for the calculation for $\mathrm{K}-\mathrm{Na}$ liquid alloys at $384 \mathrm{~K}$ has been determined from experimental value of $\mathrm{G}_{\mathrm{M}}^{\mathrm{XS}}$ and $\mathrm{H}_{\mathrm{M}}$ for equiatomic composition $(\mathrm{C}=1 / 2)$, using the equations (6) and(9) which are found as

$$
\frac{\mathrm{w}}{\mathrm{k}_{\mathrm{B}} \mathrm{T}}=0.989 \quad \text { and } \quad \frac{1}{\mathrm{k}_{\mathrm{B}}} \frac{\mathrm{dw}}{\mathrm{dT}}=0.077
$$

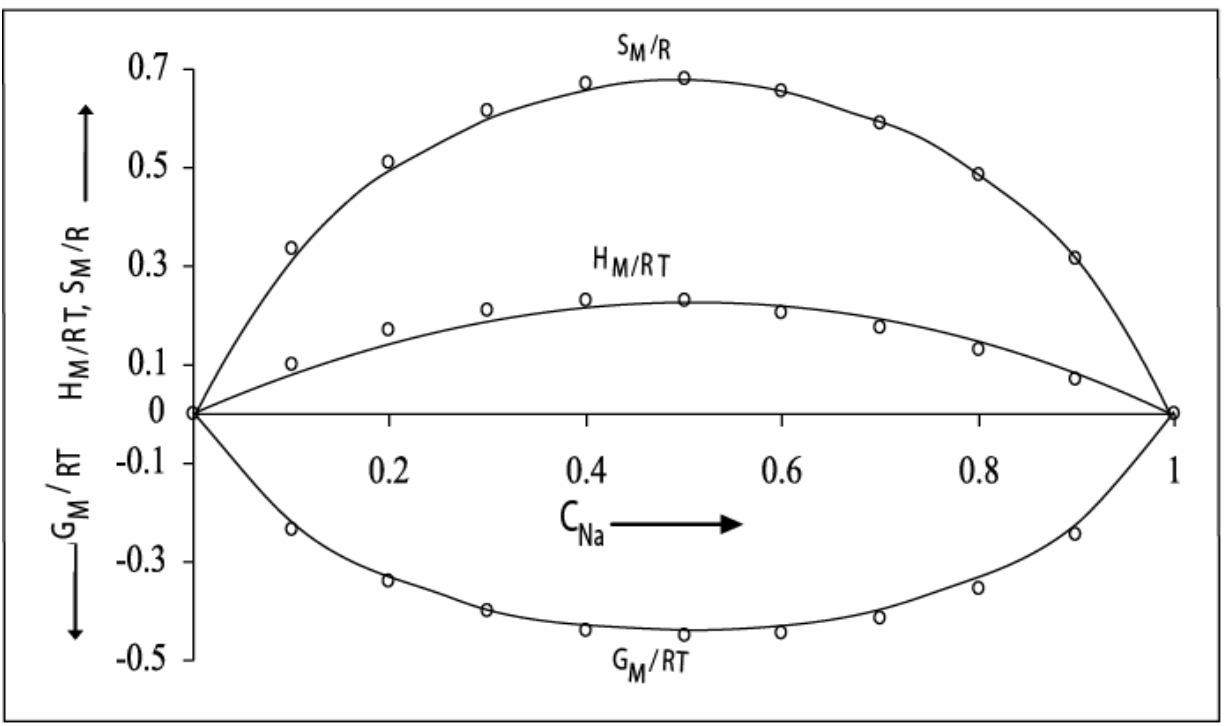

Fig. 1 : Free energy of mixing $\left(G_{M} / R T\right)$, Heat of mixing $\left(H_{M} / R T\right)$ and Entropy of mixing $\left(S_{M} / R\right)$ versus concentration of $\mathrm{Na}\left(\mathrm{C}_{\mathrm{Na}}\right)$ : Theoretical - solid curve; Experimental - circles.

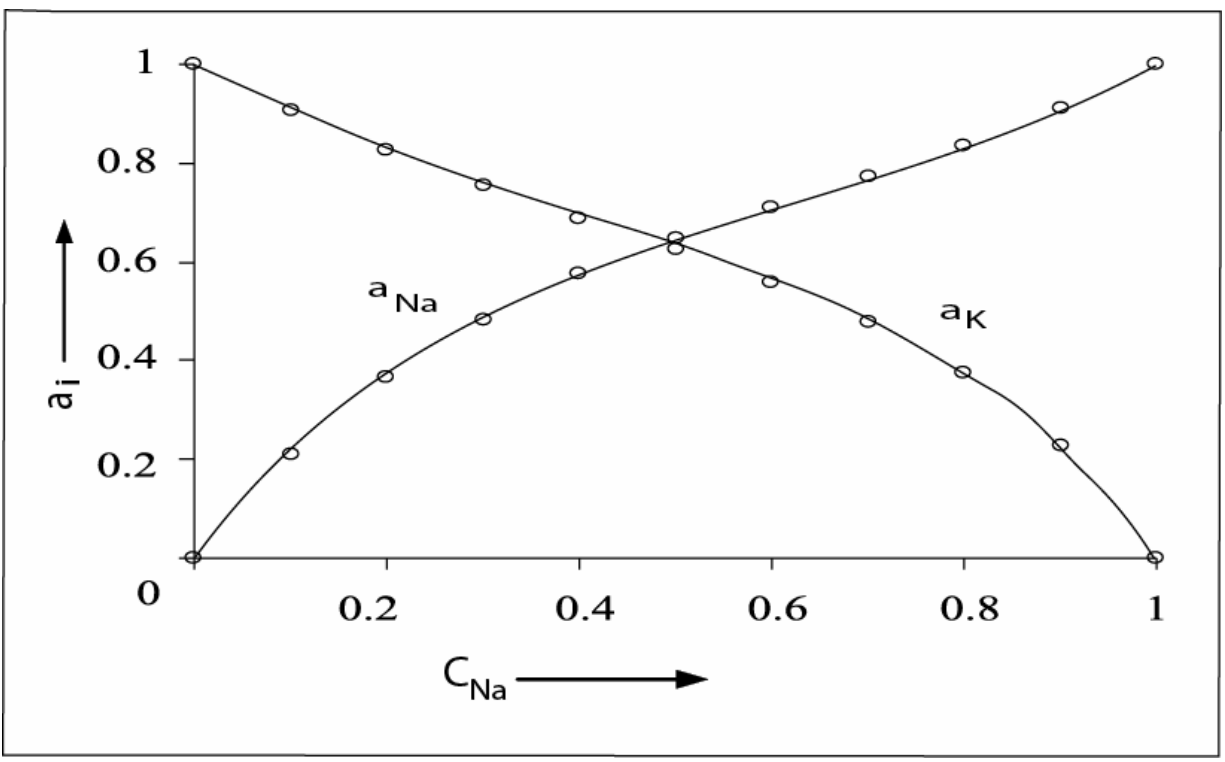

Fig. 2 : Chemical activities $\left(a_{i}\right)$ versus concentration of $\mathrm{Na}\left(\mathrm{C}_{\mathrm{Na}}\right)$ : Theoretical - solid curve; Experimental - circles. 
The free energy of mixing, heat of mixing and entropy of mixing for $\mathrm{K}-\mathrm{Na}$ liquid alloy at $384 \mathrm{~K}$ have been computed from equations (4), (9) and (10). The plot of $\mathrm{G}_{\mathrm{M}} / \mathrm{RT}, \mathrm{H}_{\mathrm{M}} / \mathrm{RT}$ and $\mathrm{S}_{\mathrm{M}} / \mathrm{R}$ versus $\mathrm{C}_{\mathrm{Na}}$ are depicted in Fig. 1. The theoretical and experimental values of $\mathrm{G}_{\mathrm{M}} / \mathrm{RT}$, $\mathrm{H}_{\mathrm{M}} / \mathrm{RT}$ and $\mathrm{S}_{\mathrm{M}} / \mathrm{R}$ are in good agreement in all concentrations of $\mathrm{Na} . \mathrm{G}_{\mathrm{M}} / \mathrm{RT}$ is minimum but $\mathrm{H}_{\mathrm{M}} / \mathrm{RT}$ and $\mathrm{S}_{\mathrm{M}} / \mathrm{R}$ are each maximum at $\mathrm{C}_{\mathrm{Na}}=0.5$, which show that $\mathrm{K}-\mathrm{Na}$ liquid alloy is symmetric about equiatomic concentration. We have used the same values of the energy parameters in Eq. (11) for the evaluation of chemical activities of the components of the alloy. There is well agreement between experimental and theoretical values of the activities of the components $\mathrm{K}$ and $\mathrm{Na}$ of the alloy (Fig. 2).

\subsection{Structural properties ( Microscopic properties )}

Using the estimated energy parameter, the theoretical values of $\mathrm{S}_{\mathrm{cc}}(0)$ are computed from Eq. (7). Fig. 3 shows a plot of the theoretical and experimental values of $S_{c c}(0)$ along with the ideal values. The theoretical values of $\mathrm{S}_{\mathrm{cc}}(0)$ are in good agreement with the experimental values of $\mathrm{S}_{\mathrm{cc}}(0)$. The result can be used to understand the nature of atomic order in binary liquid alloys. At a given composition if $\mathrm{S}_{\mathrm{cc}}(0)<\mathrm{S}_{\mathrm{cc}}^{\mathrm{id}}(0)$, ordering in liquid alloy is expected while $\mathrm{S}_{\mathrm{cc}}(0)>\mathrm{S}_{\mathrm{cc}}^{\mathrm{id}}(0)$ gives the indication of tendency of segregation.

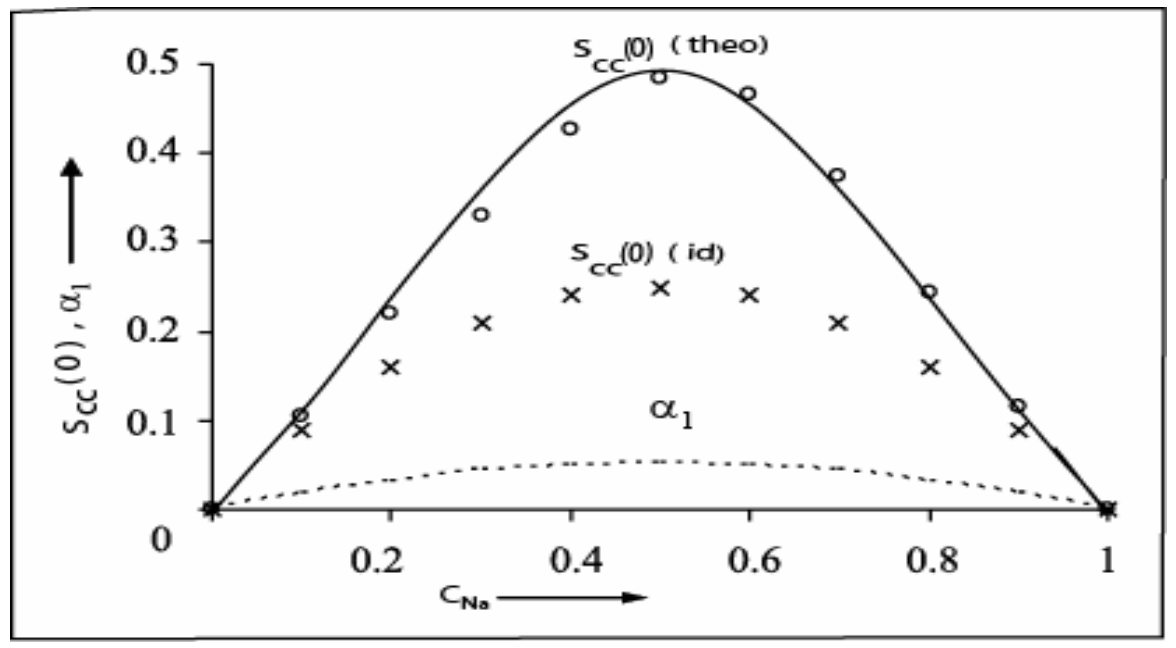

Fig. 3 : Concentration fluctuation $\left(S_{c c}(0)\right)$ versus concentration of $\mathrm{Na}\left(\mathrm{C}_{\mathrm{Na}}\right)$ : Theoretical - solid curve; Experimental - circles; Ideal- crosses and Warren-Cowley SRO parameter $\left(\alpha_{1}\right)$ versus concentration of Na $\left(\mathrm{C}_{\mathrm{Na}}\right)$

The knowledge of $\alpha_{1}$ provides an immediate insight into the nature of the local arrangement of atoms in the mixture. The minimum possible value of $\alpha_{1}$ is -1 and it indicates complete ordering of unlike atom pairing at nearest atoms. On the other hand the maximum value of $\alpha_{1}$ is +1 , which implies complete segregation leading to phase separation and $\alpha_{1}=0$ corresponds to a random distribution of atoms. Figure 3 shows that $\alpha_{1}$ is positive, maximum at $\mathrm{C}_{\mathrm{Na}}=0.5$ and $\mathrm{S}_{\mathrm{cc}}(0)>\mathrm{S}_{\mathrm{cc}}^{\mathrm{id}}(0)$ throughout whole concentration range of $\mathrm{Na}$, showing that $\mathrm{K}-\mathrm{Na}$ liquid alloy at $384 \mathrm{~K}$ is segregating. The $\mathrm{S}_{\mathrm{cc}}(0)$ are used in Eq. (12). to evaluate the ratio of the mutual and 
intrinsic-diffusion coefficients, $\frac{D_{M}}{D_{\text {id }}}$. The value of $\frac{D_{M}}{D_{i d}}$ is less than 1 in the entire range of concentration (Fig.4) which is indicative for the phase separation in the mixture.

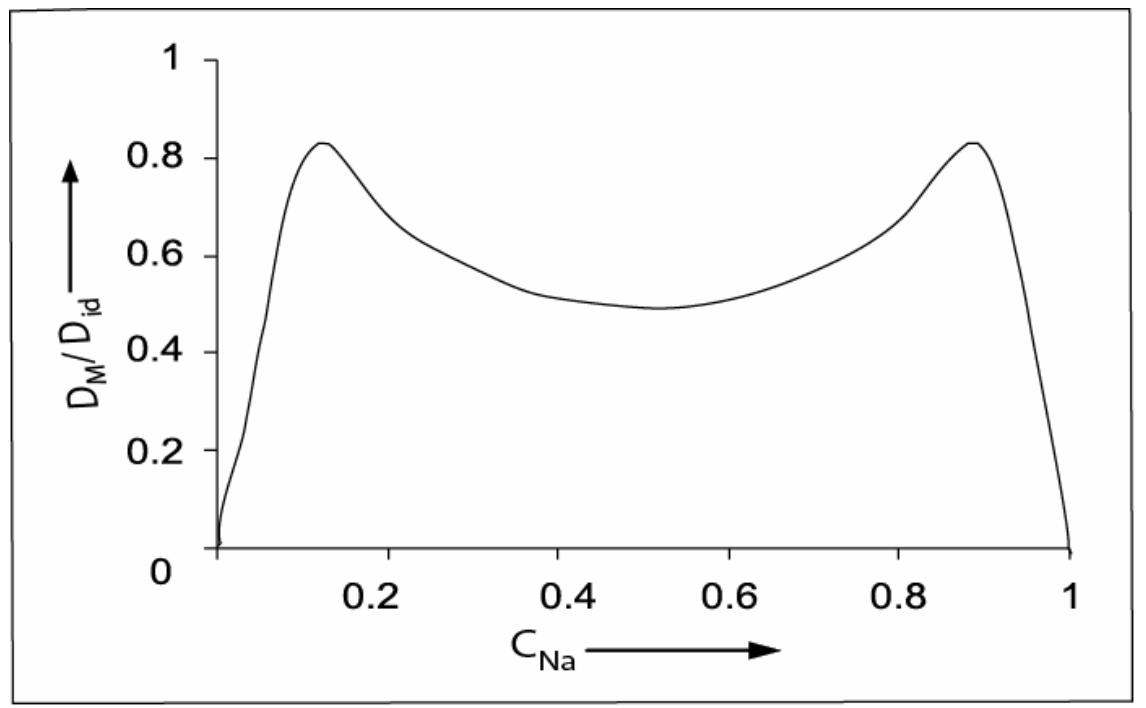

Fig. 4 : Diffusion coefficient ratio $\left(D_{M} / D_{\text {id }}\right)$ versus concentration of $\mathrm{Na}\left(C_{\mathrm{Na}}\right)$

\section{Conclusion}

The thermodynamic and structural properties of the regular $\mathrm{K}-\mathrm{Na}$ alloy at $384 \mathrm{~K}$ in liquid state are examined on the basis of simple statistical model. The analysis suggests that there is a tendency of like atom pairing in K-Na alloy in the whole range of concentration.

\section{Acknowledgment}

I.P. Koirala would like to acknowledge Dr. Devendra Adhikari, Department of Physics, M.M.A.M. Campus, Biratnagar (Tribhuvan University) Nepal for fruitful suggestions and inspiring discussions.

\section{References}

[1] R. Hultgren, P. D. Desai, D. T. Hawkins, M. Gleiser, and K. K. Kelly, Selected Values of the Thermodynamic Properties of Binary Alloys, ASM, Metal Park, ( 1973), p. 1057.

[2] J. Flory, J. Chem. Phys., 10 (1942) 51.

[3] S. Lele and P. Ramchandrarao, Metall. Trans., 12 B (1981) 659.

[4] A.S. Jordan, Metall. Trans., 1 (1970) 239.

[5] D. Adhikari, I.S. Jha. B.P. Singh, Physica B, 405 (2010) 1861.

[6] A.B. Bhatia and W.H. Hargoove, Phys. Rev. B, 10 (1974) 3186.

[7] I.S. Jha, R.N. Singh, P.L. Shrivastava, N.R. Mitra, Philos. Mag., 61 (1990) 15.

[8] R.N.Singh, I.K.Mishra, V.N. Singh, J.Phys.: Condensed Matter, 2 (1990) 8457.

[9] B.E.Warren, X-ray Diffraction, Reading MA: Addison-Wesley, (1969), p.227.

[10] J.M. Cowley, Phys. Rev., 77 (1950) 667.

[11] L.S. Darken, R.W. Gurry Physical Chemistry of Metals, McGraw Hill, New York (1953), p. 535. 